\title{
Characteristic analysis of a flash flood-affected creek catchment using LiDAR-derived DEM
}

\author{
$\underline{\text { X. Liu }}^{\text {a }}$ Z. Zhang ${ }^{\text {a }}$ and K. McDougall ${ }^{\text {a }}$ \\ ${ }^{a}$ Australian Centre for Sustainable Catchments, and Faculty of Engineering and Surveying \\ University of Southern Queensland, Toowoomba, Queensland 4350, Australia \\ Email:xiaoye.liu@usq.edu.au
}

\begin{abstract}
Flooding occurred across a large area of southern and central Queensland in December 2010 and January 2011. Intense rainfall over the Gowrie Creek catchment caused severe flash flooding through the Toowoomba CBD (Central Business District) on the afternoon of Monday, 10 January 2011, taking lives and damaging the community. Flash floods are sudden and unexpected floods that arise from intense rainfall, generally over a small, steep catchment area. Smaller and steeper catchments have shorter critical storm duration, and they respond more quickly to rainfall events. The resulting flood wave is characterized by very high water flows and velocities and abrupt water level rises, leading to extremely hazardous conditions. Effective flash flood forecasting for specific locations is a big challenge because of the behaviour of intense thunderstorms. A flash flood forecasting and warning system calls for accurate spatial information on catchment characteristics. A high-resolution DEM is a key spatial dataset for the characterization of a catchment to design possible flood mitigation measures.
\end{abstract}

The characteristics of a catchment have a strong influence on its hydrological response. The nature of floods is dependent on both the intensity and duration of the rainfall and the catchment characteristics such as catchment area, drainage patterns and waterway steepness. Therefore, analysis of catchment characteristics is critical for hydrologic modelling and planning for flood risk mitigation. The analysis of catchment characteristics can support hydrological modelling and planning for flood risk mitigation. For example, the shape indices of sub-catchments can be used to compare the hydrological behaviour of different subcatchments. The longitudinal profiles of the creeks illustrate the slope gradients of the waterways. A hypsometric curve for each sub-catchment provides an overall view of the slope of a catchment and is closely related to ground slope characteristics of a catchment. Airborne light detection and ranging (LiDAR), also referred to as airborne laser scanning (ALS), is one of the most effective means of terrain data collection. Using LiDAR data for generation of DEMs is becoming a standard practice in the spatial science community. This study used airborne LiDAR data to generate a high-resolution DEM for characteristic analysis of Gowrie Creek catchment in Toowoomba, Queensland, Australia, which was affected by a flash flood in January 2011. Drainage networks and sub-catchment boundaries were extracted from LiDAR-derived DEM. Catchment characteristics including sub-catchment areas and shape indices, longitudinal profiles of creeks and hypsometric curves of sub-catchments were calculated and analysed.

Keywords: Flash flood, Digital elevation model, DEM, LiDAR, Catchment, Hydrology, Gowrie Creek, Toowoomba 


\section{INTRODUCTION}

A catchment, also referred to as a drainage basin or watershed (Maidment, 2002; Liu and Zhang, 2011), is an area of land where all the water flows to a common point (catchment outlet) (Wilson and Gallant, 2000; BMT WBM, 2011). It is one of the most important elements in hydrological analysis (Liu and Zhang, 2011). The characteristics of a catchment have a strong influence on its hydrological response (Musy and Higy, 2011). The nature of rainfall floods is dependent on both the intensity and duration of the rainfall and the catchment characteristics such as catchment area, drainage patterns and waterway steepness (BMT WBM, 2011; ICA, 2011). Therefore, analysis of catchment characteristics is critical for hydrologic modelling and flood risk mitigation. Catchment characterization including drainage network and catchment boundary extraction relies on a high-quality DEM (digital elevation model) (Liu and Zhang, 2010; Liu and Zhang, 2011). Airborne light detection and ranging (LiDAR), also referred to as airborne laser scanning (ALS), is one of the most effective means of terrain data collection. Using LiDAR data for generation of DEMs is becoming a standard practice in the spatial science community (Liu, 2008).

Flooding occurred across a large area of southern and central Queensland in December 2010 and January 2011 (SKM, 2011). Intense rainfalls over the Gowrie Creek catchment caused severe flash flooding through the Toowoomba CBD (Central Business District) on the afternoon of Monday, 10 January 2011, taking lives and damaging the community. Flash floods are sudden and unexpected floods that arise from intense rainfall, generally over a small, steep catchment area. Smaller and steeper catchments have shorter critical storm duration, and they respond more quickly to rainfall events. The resulting flood wave is characterized by very high water flows and velocities and abrupt water level rises, leading to extremely hazardous conditions (ICA, 2011). The primary objective of flash flood warning is to provide timely warnings for potentially affected areas to enable actions to mitigate the risk of property damaging and life loss (SKM, 2011). Effective flash flood forecasting for specific locations is a big challenge because of the behaviour of intense thunderstorms (Hapuarachchi et al., 2011; SKM, 2011). A flash flood forecasting and warning system calls for accurate spatial information on catchment characteristics (SKM, 2011). High-resolution DEM is a key spatial dataset for the characterization of a catchment to design possible flood mitigation measures. This study aims to use Airborne LiDAR data to generate a high-resolution DEM for characteristic analysis of Gowrie Creek catchment. Drainage networks and sub-catchment boundaries were extracted from LiDAR-derived DEM, catchment characteristics including sub-catchment areas and shape indices, longitudinal profiles of creeks and hypsometric curves of sub-catchments were calculated and analysed.

\section{MATERIALS AND METHODS}

\subsection{Study Area}

The study area is in the region of Toowoomba City, approximately $130 \mathrm{~km}$ west of Brisbane, Queensland, Australia. The Toowoomba City is located on the crest of the Great Dividing Range around 700 metres above sea level. The area of Toowoomba City is on the edge of the Condamine Catchment and is also part of the Murray-Darling Basin in southern Queensland (Phillips and Moller, 1995). There are a number of ridges and valleys within the area of Toowoomba City which divide it into several distinct sub-catchments. Gowrie Creek together with its tributaries including East Creek, West Creek and Black Gully forms the Gowrie Creek system (or the Gowrie Creek catchment) (Kilminster et al., 1999; TCC, 2002). East and West Creeks drains much of the city and suburban area of Toowoomba (SKM, 2011) and converge just to the north of the CBD. Black Gully joins Gowrie Creek approximately $2 \mathrm{~km}$ downstream of the confluence of East and West Creeks (ICA, 2011) as shown in Figure 1. The Gowrie Creek catchment as shown in Figure 1 was the main area impacted by the flash flood event of 10 January 2011.

\subsection{Data}

LiDAR data were collected using an Optech ALTM Gemini LiDAR system at a flying height of 1,200 m above ground between the 29 June and 16 July 2010. The laser scanner was configured to record up to 4 returns for one laser pulse. The average point separation is $1.0 \mathrm{~m}$. The LiDAR data used for this project was documented as $0.15 \mathrm{~m}$ for vertical accuracy and $0.22 \mathrm{~m}$ for horizontal accuracy. The LiDAR data were classified into ground and non-ground points by the vendor and were delivered in binary LAS file format (Schmap, 2010). 

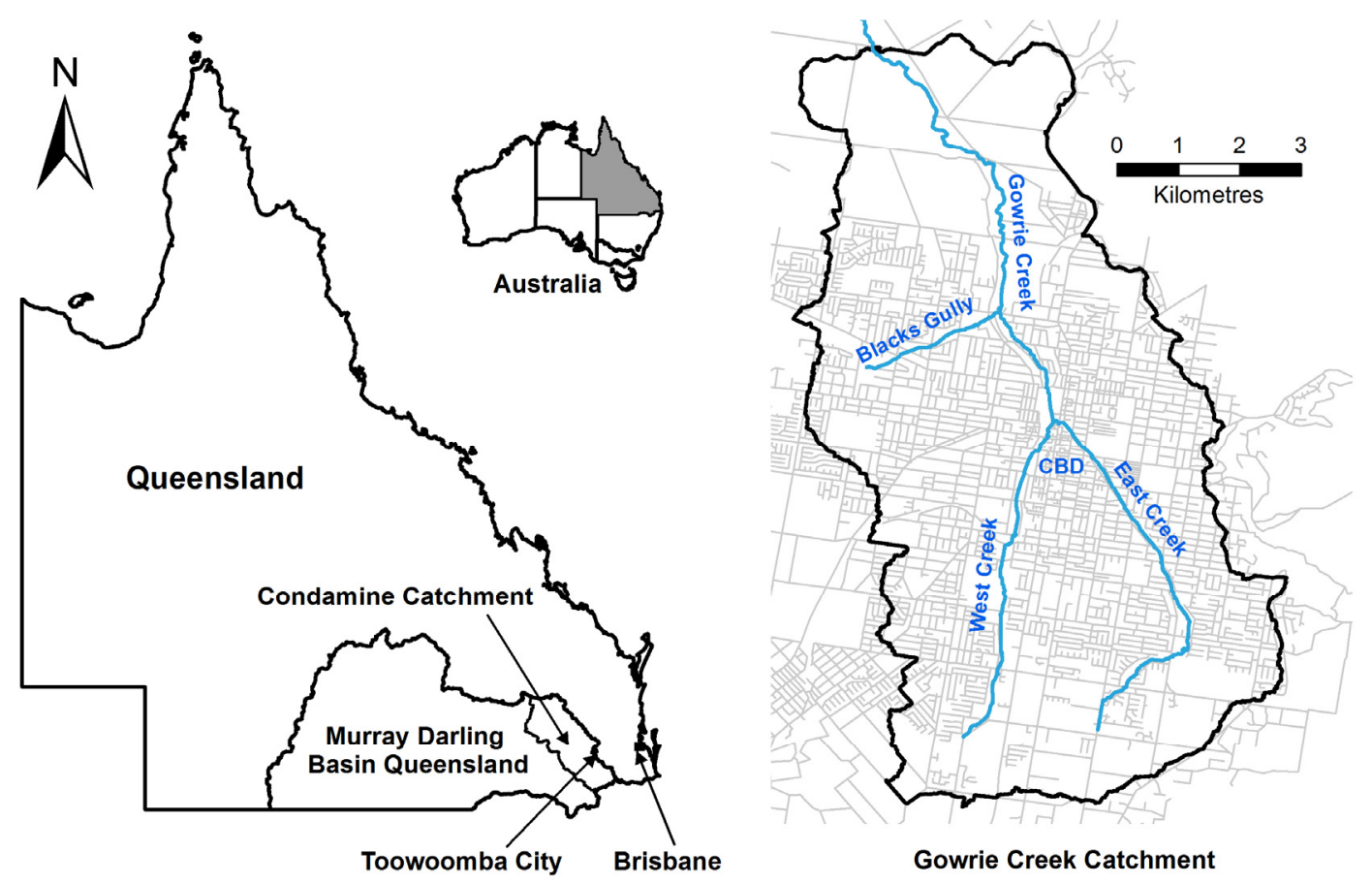

Figure 1. Study area showing the location of Gowrie Creek Catchment within the area of Toowoomba City in southeast Queensland, Australia.

\subsection{Methods}

A DEM with one metre horizontal resolution (grid size) was generated from the LiDAR ground data in the study area by using an IDW (inverse distance weighted) interpolation method in ArcGIS 10 software. The extraction of catchment boundaries and drainage networks from LiDAR-derived DEM was carried out using the Arc Hydro extension within ArcGIS 10. Arc Hydro tools are based on the most widely used D8 algorithm. The main steps include sink filling, identification of flow direction, calculation of flow accumulation and stream definition. Once the drainage networks and catchment including sub-catchment boundaries were extracted, other characteristics of catchments such as surface area, shape indices, hypsometric curve, and creek profile can be calculated. Among the shape indices, the most well known are probably the compactness index (Equation 1), circularity (Equation 2), Form factor (Equation 3) and elongation (Equation 4) (Bárdossy and Schmidt, 2002).

$$
\begin{aligned}
& C=\frac{P}{2 \sqrt{\pi A}} \\
& c=\frac{4 \pi A}{P^{2}} \\
& F=\frac{A}{L^{2}} \\
& E=\frac{2}{L} \sqrt{\frac{A}{\pi}}
\end{aligned}
$$

where $\mathrm{P}$ and $\mathrm{A}$ are the perimeter and area of the catchment, and $\mathrm{L}$ is the maximum length of the catchment parallel to the main drainage lines. It should be noted that the circularity index (Equation 2) can be derived from the compactness index (Equation 1) and the elongation (Equation 4) can be derived from the form factor (Equation 3) (Bárdossy and Schmidt, 2002). 
The longitudinal profiles of the East Creek, West Creek, Blacks Gully and Gowrie Creek were produced using a method developed by Strahler (1952), which represent the variation in elevation with distance of a creek. The Hypsometric curve representing an overall view of the slope of each catchment was also generated from the DEM.

\section{RESULTS AND DISCUSSION}

Catchment boundaries derived from the DEM are shown in Figure 2, which includes the sub-catchment areas of East Creek, West Creek, Blacks Gully, Gowrie Creek and a sub-catchment area in the middle (called MidGowrie Creek catchment here). Figure 2 also shows the drainage networks derived from the DEM. The area and shape indices for each sub-catchment are listed in Table 1. The East and West Creek are the two biggest sub-catchments, with area of $15.59 \mathrm{~km} 2$ and $15.87 \mathrm{~km} 2$ respectively. The area of Mid-Gowrie Creek, together with the area of Gowrie Creek is usually called the Gowrie Creek sub-catchment, covering an area of $18.38 \mathrm{~km} 2$. The catchment area of Blacks Gully has an area of $6.26 \mathrm{~km} 2$. All these sub-catchments are characterized by moderately steep side slopes with rainfall runoff travelling quickly over impervious ground to the watercourse. The waterways of creeks are steep and consequently flow velocities within the stream are quite high (BMT WBM, 2011).

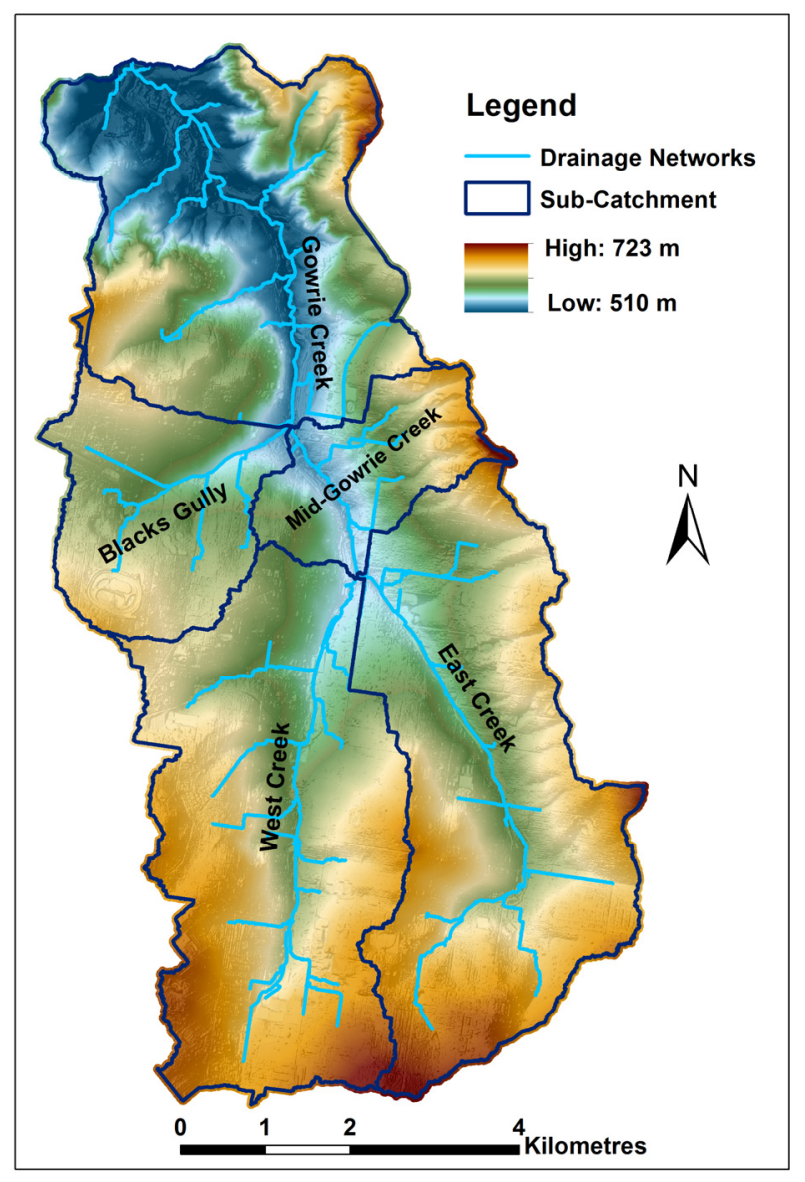

Figure 2. Study area showing the location of Gowrie Creek Catchment within the area of Toowoomba City in southeast Queensland, Australia.

The shape indices listed in Table 1 can be used to characterize flows and to compare the hydrological behaviour of different catchments (McArthur and Ehrlich, 1977; Breyer and Snow, 1992; Bárdossy and Schmidt, 2002; Musy and Higy, 2011). The compactness index is defined as the ratio of the perimeter of a catchment to the perimeter of a circle with the same surface area. If the value of the compactness index is close to 1, the catchment approaches a circular shape (Musy and Higy, 2011). Bigger values of compactness indices for the East Creek and West Creek catchments (as shown in Table 1) indicates both catchments are elongated in shape. Circularity index is calculated by dividing the catchment area by the area of a circle with 
the same perimeter as the basin (Miller, 1957). Form factor is defined as the ratio of catchment area to the square of basin length (Sameena et al., 2009). Lower values of both circularity and form factor indices (as shown in Table 1) also indicate the East and West Creek catchments have long narrow shapes. The elongation ratio, defined as the ratio of the diameter of a circle with the same area as the catchment to the maximum catchment length (Schumm, 1956), gave values between 0.7 and 1.0 shown in Table 1 . Values of the elongation ratio in the range of 0.7 to 0.8 are typical of regions with steep ground slopes, whereas values near to 1.0 are generally associated with low relief (Schumm, 1956; Sameena et al., 2009).

Table 1. Sub-catchment areas and catchment shape indices

\begin{tabular}{lccccc}
\hline Sub-Catchment & Area $\left(\mathrm{km}^{2}\right)$ & Compactness & Circularity & Form factor & Elongation \\
\hline East Creek & 15.59 & 2.39 & 0.18 & 0.41 & 0.72 \\
West Creek & 15.87 & 2.44 & 0.17 & 0.38 & 0.70 \\
Mid-Gowrie Creek & 3.92 & 2.19 & 0.21 & 0.38 & 0.70 \\
Blacks Gully & 6.26 & 2.23 & 0.20 & 0.56 & 0.84 \\
Gowrie Creek & 14.46 & 1.90 & 0.28 & 0.71 & 0.95 \\
\hline
\end{tabular}

The longitudinal profiles of the East Creek, West Creek, Blacks Gully and Gowrie Creek are shown in Figure 3 , depicting the down slope gradients of the creeks. The curved profiles of the East Creek and West Creek exhibit steeper slope up stream, giving way to relatively gentle slope in the down stream. The steeper upstream slopes of the East and West Creeks ran surface water very quickly to the down streams. The profiles of the Blacks Gully and Gowrie Creek approach constant slopes.
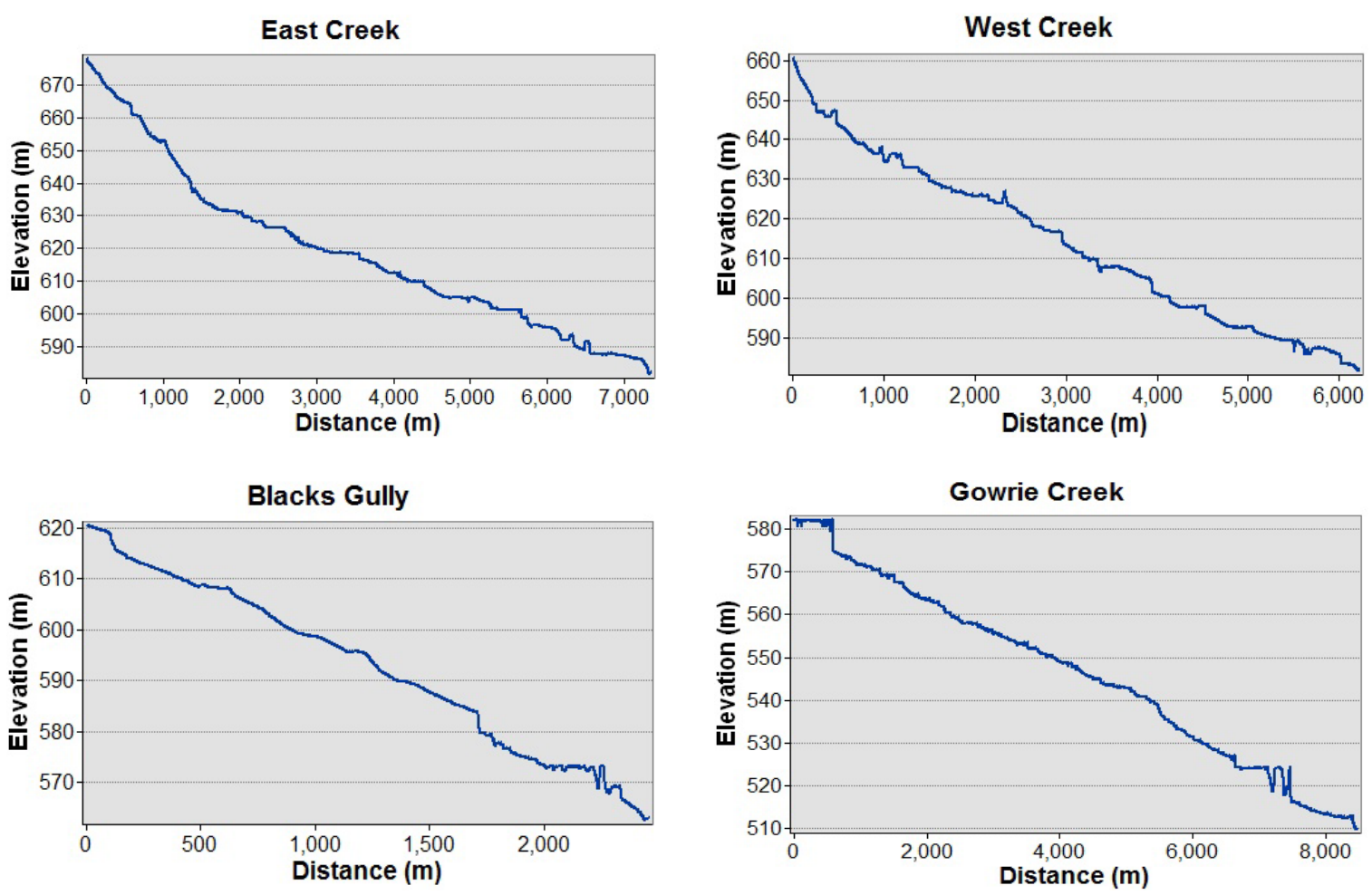

Figure 3. Longitudinal profiles of the East Creek, West Creek, Blacks Gully and Gowrie Creek. 
Hypsometric curves plotted for each sub-catchment are shown in Figure 4. A hypsometric curve provides an overall view of the slope of a catchment, and thus the relief. It represents the distribution of the surface area of the catchment according to height (Strahler, 1952; Musy and Higy, 2011). In Figure 4 (a), the horizontal axis shows the cumulated surface area (the percentage of the surface area) that lies above the elevation as represented on the vertical axis. The East and West Creeks sub-catchments show an overall higher surface area and steeper slopes. In Figure 4 (a), however, it is difficult to compare catchments with different sizes and surface heights. Figure 4 (b) is an alternative, showing the proportion of total catchment area above any relative height in the range between maximum and minimum height of a catchment (Strahler, 1952; Schumm, 1956; Dowling et al., 1998; Musy and Higy, 2011). Characteristics of the hypsometric curve are closely related to ground slope characteristics of a catchment. The hypsometric curves for the East and West Creeks have steeper slope in the mid-section of the catchments, but the upper parts of the curves are steepest of all in the region corresponding to the highest area of the catchments. The curve of Blacks Gully catchment has an overall steeper slope. The curves for both the Mid-Gowrie and Gowrie catchments are mostly gentler slope, but steeper at both ends.
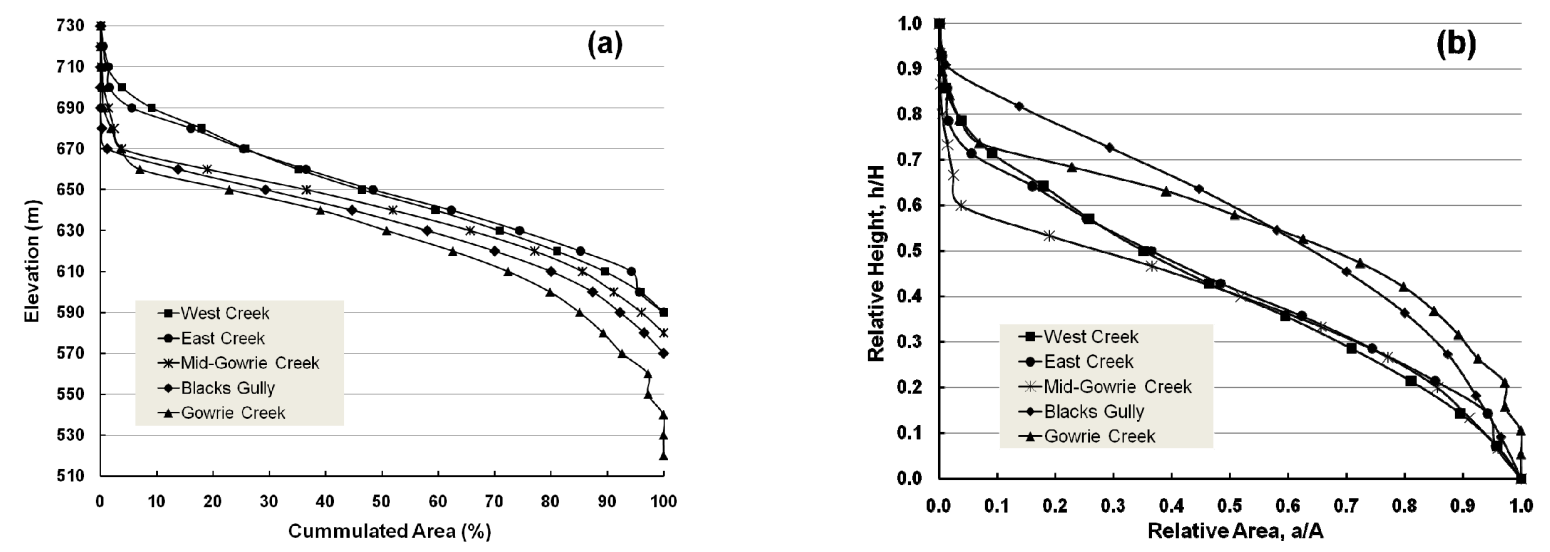

Figure 4. Hypsometric and normalised hypsometric curves for the sub-catchments of East Creek, West Creek, Mid-Gowrie Creek, Blacks Gully and Gowrie Creek.

For the same rainfall, theoretically, a catchment with a long narrow shape will result in lower peak flows at the outlet, because it requires more time for the water to reach the outlet (Musy and Higy, 2011). In reality, however, the behaviour of rainfall floods is also determined by the intensity and duration of the rainfalls and by the response of the catchment upstream of the point of interest. The smaller and steeper a catchment, the more quickly it gathers and conveys surface runoff to the catchment outlet (ICA, 2011). Intense rainfalls and steep narrow-sided waterways in East and West Creek catchments resulted in flash flooding in January 2011. The analysis of catchment characteristics can support hydrological modelling and planning for flood risk mitigation.

\section{CONCLUSION}

The adequate extraction and analysis of catchment characteristics is one of the critical steps for hydrological modelling and planning for flood risk mitigation. High-resolution DEM is a key spatial dataset for the characterization of a catchment. This study used a LiDAR-derived high-resolution DEM to extract and analyze key catchment characteristics in flash flood-affected Gowrie Creek catchment area. The shape indices of sub-catchments can be used to compare the hydrological behaviour of different sub-catchments. The longitudinal profiles of the creeks illustrate the slope gradients of the waterways. Hypsometric curve for each sub-catchment provides an overall view of the slope of a catchment and are closely related to ground slope characteristics of a catchment.

\section{ACKNOWLEDGMENTS}

We would like to thank the Toowoomba Regional Council for providing the LiDAR data for use in this study. 
Liu et al., Characteristic Analysis of a Flash Flood-affected Creek Catchment using LiDAR-derived DEM

\section{REFERENCES}

Bárdossy, A., and Schmidt, F. (2002). GIS approach to scale issues of perimeter-based shape indices for drainage basins. Hydrological Sciences Journal, 47(6), 931-942.

BMT WBM (2011). Technical report on the Toowoomba flood of 10 January 2011, pp.64. BMT WBM Pty Ltd, Brisbane, Queensland, Australia.

Breyer, S.P., and Snow, R.S. (1992). Drainage basin perimeters: a fractal significance. Geomorphology, 5, 143-157.

Dowling, T.I., Richardson, D.P., O'Sullivan, A., Summerell, G.K., and Walker, J. (1998). Application of the hypsometric integral and other terrain based metrics as indicators of catchment health: A preliminary analysis, pp.52. CSIRO Land and Water, Canberra, Australia.

Hapuarachchi, H.A.P., Wang, Q.J., and Pagano, T.C. (2011). A review of advances in flash flood forecasting. Hydrological Processes, DOI: 10.1002/hyp.8040

ICA (2011). The nature and causes of flooding in Toowoomba 10 January 2011, pp.78. Insurance Council of Australia (ICA) Hydrology Panel, Sydney, Australia.

Kilminster, N., Russell, R., Kilminster, C., and Russell, I. (1999). A cost benefit analysis of the revitalisation of the Gowrie Creek catchment. Occasional Paper, 6(3), 1-68.

Liu, X. (2008). Airborne LiDAR for DEM generation: some critical issues. Progress in Physical Geography, 32(1), 31-49.

Liu, X., and Zhang, Z. (2010), Extracting drainage network from high resolution DEM in Toowoomba, Queensland. Proceedings of Queensland Surveying and Spatial Conference, Brisbane, Queensland, Australia.

Liu, X., and Zhang, Z. (2011). Drainage network extraction using LiDAR-derived DEM in volcanic plains. Area, 43(1), 42-52.

Maidment, D.R. (2002). Arc Hydro: GIS for Water Resources, pp.203. ESRI Press, Redlands, CA.

McArthur, D.S., and Ehrlich, R. (1977). An efficiency evaluation of four drainage basin shape ratios. The Professional Geographer, 29(3), 290-295.

Miller, V.C. (1957). A quantitative geomorhic study of drainage basin characteristics in the Clinch Mountain area, Virginia and Tennessee, pp.30. Department of Geology, Clumbia University, New York.

Musy, A., and Higy, C. (2011). Hydrology: A Science of Nature, pp.326. CRC Press, Boca Raton, FL, USA.

Phillips, N., and Moller, G. (1995). An ecological and physical assessment of the condition of streams in the upper Condamine River catchment, pp.74. Department of Primary Industries, Brisbane, Queensland, Australia.

Sameena, M., Krishnamurthy, J., Jayaraman, V., and Ranganna, G. (2009). Evaluation of drainage networks developed in hard rock terrain. Geocarto International, 24(5), 397-420.

Schmap (2010). LiDAR Report for Toowoomba Regional Council 2010 LiDAR Capture Project, pp.7. Schlencker Mapping Pty Ltd, Brisbane, Queensland, Australia.

Schumm, S.A. (1956). Evolution of drainage systems and slopes in badlands at Perth Amboy, New Jersey. Bulletin of the Geological Society of America, 67, 597-646.

SKM (2011). Hydrological advice to commission inquiry regarding 2010/11 Queensland floods: Toowoomba and Lockyer Valley flash flood events of 10 and 11 January 2011, pp.77. Sinclair Knight Merz Pty Ltd, Brisbane, Australia.

Strahler, A.N. (1952). Hypsometric (area-altitude) analysis of erosional topography. Bulletin of the Geological Society of America, 63, 1117-1142.

TCC (2002). An assessment of cultural heritage values associated with Gowrie Creek waterways, Toowoomba City Council, Toowoomba, Queensland, Australia.

Wilson, J.P., and Gallant, J.C. (2000). Digital terrain analysis, in Wilson, J.P., and Gallant, J.C. (Eds), Terrain Analysis: Principles and Applications, John Wiley \& Sons, Inc, New York, 1-27. 